\title{
O uso da energia solar para controle de clima e economia de energia em estufas: uma revisão
}

A redução dos custos de aquecimento é um grande desafio para os produtores que utilizam estufas. Diversas técnicas têm sido aplicadas para reduzir custos de aquecimento e reduzir o uso do carvão como fonte de energia. Este estudo apresenta uma revisão de diferentes técnicas de economia de energia que podem ser aplicadas para reduzir os custos de aquecimento, como em relação à forma, orientação geográfica, anglo de inclinação do teto, materiais de cobertura, uso de telas térmicas, módulos fotovoltaicos, coletores solares térmicos, híbridos, sistemas PV/T, materiais de mudança de fase (PCM), técnicas de armazenamento de calor subterrâneas, bombas de calor energeticamente eficiente e materiais de fachadas alternativos. A principal causa da demanda de aquecimento das estufas se dá pelas características de construção pobres e resistência térmica insuficiente dos materiais de fachada utilizados nos sistemas atuais de estufas. Atualmente, o carvão é amplamente utilizado para aquecimento de estufas convencionais, porém, seu uso causa quantidades significativas de emissões de carbono, gerando problemas ambientais. Portanto, soluções definitivas baseadas em tecnologias de energia renovável e sustentável são necessárias para reduzir a energia consumida no setor de estufas e para deter as emissões de carbono relacionadas ao efeito estufa. O investimento em uma estufa solar fornece um retorno positivo para os agricultores após um período que varia entre 4 e 8 anos, dependendo das condições climáticas e do tipo de cultura.

Palavras-chave: Controle de clima; Energias renováveis; Estufa Solar; Secagem; Radiação Solar.

\section{The use of solar energy for climate control and energy saving in greenhouses: a review}

\begin{abstract}
Reducing heating costs is a major challenge for producers who works with greenhouses. Several techniques have been applied to reduce the costs and the use of coal as an energy source. This study presents a review of different energy saving techniques that can be applied to reduce heating costs, such as in terms of shape, geographic orientation, large ceiling angle, roofing materials, use of thermal screens, photovoltaic modules, solar thermal collectors, hybrids, PV/T systems, phase change materials (PCM), underground calorie storage techniques, energy efficient heat pumps and alternative façade materials. The main cause of the heating demand of the greenhouses is due to the poor construction characteristics and insufficient thermal resistance of the facade materials used in the current greenhouse systems. Currently, coal is widely used for heating conventional greenhouses, however, its use causes carbon load sources, generating environmental problems. Therefore, definitive solutions based on renewable and sustainable energy technologies are necessary to reduce the energy consumed in the greenhouse sector and to stop carbon discharging related to the greenhouse effect. The investment in a solar greenhouse offers a positive return for farmers after a period that varies between 4 and 8 years, depending on climatic conditions and the type of crop.
\end{abstract}

Keywords: Climate control; Renewable energies; Solar greenhouse; Drying; Solar radiation.

Topic: Construções e Arquitetura Sustentáveis

Reviewed anonymously in the process of blind peer
Received: 04/07/2021

Approved: $27 / 07 / 2021$
Camila Piacitelli Tieghi (D)

Universidade Estadual Paulista Júlio de Mesquita Filho, Brasil http://lattes.cnpq.br/5740229034210537

http://orcid.org/0000-0001-8060-5373

camila.piacitelli@unesp.br

Alexandre Dal Pai (D)

Universidade Estadual Paulista Júlio de Mesquita Filho, Brasil

http://lattes.cnpq.br/9708248454957558

http://orcid.org/0000-0002-1283-901X

dal.pai@unesp.br

Fernando de Lima Caneppele (10)

Universidade de São Paulo, Brasil

http://lattes.cnpq.br/6427310914182859

http://orcid.org/0000-0003-4498-8682

caneppele@usp.br

\section{Referencing this:}

TIEGHI, C. P.; PAI, A. D.; CANEPPELE, F. L.. O uso da energia solar para controle de clima e economia de energia em estufas: uma revisão. Revista Ibero Americana de Ciências Ambientais, v.12, n.7, p.184194, 2021. DOI: http://doi.org/10.6008/CBPC21796858.2021.007.0018 


\section{INTRODUÇÃO}

A utilização de combustíveis fósseis como fonte de energia tem sido repensada atualmente, pois é uma fonte finita e poluente de energia. No sentido de utilizar fontes alternativas de energia, hoje se consegue trabalhar com energia eólica, maremotriz, biomassa, solar, etc. A energia solar, além de ser uma fonte renovável, é uma fonte sustentável e abundante no Brasil. A incidência de energia solar anual é alta se comparado a outros países onde projetos para exploração de recursos solares, alguns contando com fortes incentivos governamentais, são amplamente difundidos. Os valores médios anuais de irradiação solar global que incidente no território brasileiro variam entre 3.500 a $6.250 \mathrm{kWh} / \mathrm{m}^{2}$.dia. Como comparativo, na Alemanha incide entre 900 a $1.250 \mathrm{kWh} / \mathrm{m}^{2}$.dia, França entre 900 a $1.650 \mathrm{kWh} / \mathrm{m}^{2}$.dia e Espanha entre 1.200 a $1.850 \mathrm{kWh} / \mathrm{m}^{2}$.dia (PEREIRA et al., 2006; PEREIRA et al., 2017). A energia proveniente do Sol pode ser aproveitada para vários fins, como conversão energética, térmica e conforto térmico. Na área agronômica, a energia solar é utilizada para diversos fins, como bombeamento de água na irrigação, resfriadores para produção leiteira, cercas elétricas para manejo de gado, secagem de grãos, madeira, frutas, etc. Vários pesquisadores ao redor de mundo têm estudado a energia solar para uso em estufas, visando a economia de energia e consequente aumento da lucratividade. Neste sentido, o uso de tecnologias, materiais e design de estufas visando o aproveitamento da energia solar vem sendo uma preocupação dos produtores. No sentido de maximizar o ganho energético solar e reduzir o impacto ambiental, vários estudos tem sido feitos em relação à orientação geográfica da estufa, anglo de inclinação do teto, materiais de cobertura, uso de telas térmicas, módulos fotovoltaicos, coletores solares térmicos, híbridos, sistemas $\mathrm{PV} / \mathrm{T}$, materiais de mudança de fase (PCM), técnicas de armazenamento de calor subterrâneas, bombas de calor energeticamente eficiente e materiais de fachadas alternativos (GOLZAR et al., 2018; MOHAMMADI et al., 2018; TAKI et al., 2016; NTINAS et al., 2014; ABDULMALEK et al., 2018; SALES et al., 2016; STANGERLIN et al., 2009; HAMDI et al., 2018; BADAOUI et al., 2019; WILKINS et al., 2018; GOURDO et al., 2019; AHAMED et al., 2019; CUCE et al., 2016; MOBTAKER et al., 2016; TAKI et al., 2018). Tudo para melhorar o isolamento térmico e gerar energia. Essas são soluções baseadas em tecnologias de energia renovável e sustentável para reduzir a energia consumida no setor de estufas e para deter as emissões de carbono relacionadas ao efeito estufa causado pelo uso de combustíveis fósseis.

Este estudo teve como objetivo realizar uma revisão integrativa de literatura baseada em literatura especializada sobre o uso da energia solar para controle de clima e economia de energia em estufas.

\section{REVISÃO TEÓRICA}

\section{O uso da radiação solar em estufas}

A radiação solar é um fator dominante para prover luz e temperatura em qualquer ambiente. A intensidade de radiação solar incidente em uma estufa, em um determinado momento e local, depende de sua forma, orientação, ângulo de inclinação do telhado, material estrutural, etc. (CUCE et al., 2016; AHAMED et al., 2019). O clima de uma estufa é caracterizado pela temperatura, umidade e concentração de CO2 (TAKI 
et al., 2018). Em estufas tradicionais, para controlar cada parâmetro interno, são utilizados aquecedores, resfriadores, ventiladores, iluminação artificial, entre outros fatores que consomem grandes quantidades de energia e, além disso, o uso de combustíveis fosseis é amplamente utilizado nos dias atuais. O controle do clima em estufas proporciona um ambiente muito adequado para o cultivo de todos os tipos de culturas, resultando em maior rendimento, qualidade e no aumento da disponibilidade de mercado dos produtos. Outro uso da estufa é para secagem. A secagem de produtos agrícolas é feita com a intenção de neutralizar a atividade de vários organismos microscópicos, aumentar o tempo de armazenamento, melhoria da qualidade do produto e reduzir perdas pós-colheita. $\mathrm{O}$ uso de estufas solares para secagem se tornou atrativo, pois a secagem solar aberta possui algumas desvantagens pelo fato de que as culturas ficam expostas ao tempo, animais e pragas, o que pode comprometer a produção do agricultor. A secagem em estufa solar fornece boa qualidade, cor e sabor dos produtos secos (STANGERLIN et al., 2009; SALES et al., 2016; BADAOUI et al., 2019; HAMDI et al., 2018; WILKINS et al., 2018).

A utilização de estufas proporciona várias vantagens, porém, os custos de investimento, mão de obra e energia por unidade de área são muito maiores em uma indústria de efeito estufa do que em qualquer outro setor agrícola (MOHAMMADI et al., 2018).

Visando economizar energia e consequente aumento do lucro do produto final, vários estudos estão sendo feitos utilizando a radiação solar como fonte de energia para o uso em estufas. No projeto de estufas solares, os engenheiros tentam captar o máximo de radiação solar durante o dia e reduzir o calor perdido a noite. A estufa solar tem algumas alterações em comparação com uma estufa convencional, tais como: melhor valor de isolamento e melhor cobertura de transmissão de luz, ventilação com recuperação de calor, aquífero, extração de calor, bomba de calor, caldeira, fornecimento de dióxido de carbono e motor a gás ou motor elétrico (AHAMED et al., 2019; CUCE et al., 2016; MOBTAKER et al., 2016).

Os sistemas de estufa sustentáveis, comercialmente competitivos e ambientalmente saudáveis, dependem da correta análise das necessidades do produtor e gestão de equipamentos e materiais construtivos que promovam um retorno financeiro baixo após a implantação de uma estufa solar.

\section{METODOLOGIA}

Este estudo constitui-se de uma revisão integrativa da literatura especializada, realizada em abril de 2019, no qual realizou-se uma consulta e seleção de conteúdos científicos presentes nas plataformas Science Direct, SciELO e pelo sistema P@rthenon da biblioteca da Faculdade de Ciências Agronômicas de Botucatu FCA UNESP, que congregam informações bibliográficas, eletrônicas e digitais. A busca da bibliografia foi feita através de busca bibliográfica entre os anos de 2009 a 2019. A estratégia de busca na base de dados Science Direct e SciELO foi buscando-se as seguintes palavras-chaves: (Solar AND Greenhouses). Na base de dados da FCA UNESP, P@rthenon, as palavras-chave buscadas foram (Estufa AND Solar). A seleção dos artigos baseou-se na conformidade dos limites dos assuntos aos objetivos deste trabalho, tendo sido desconsiderados aqueles com data de publicação anterior à 2009. Foram considerados critérios de inclusão os estudos de revisão bibliográfica e experimentais que tenham sido publicados em português ou inglês. 


\section{Estufas solares}

O modo de operação de estufas solares é por convecção natural (modo passivo) ou foçada (modo ativo). No modo passivo, a saída da umidade interna é feita utilizando a circulação natural de ar, enquanto que no modo ativo, a convecção do ar é forçada através de um exaustor.

Com o intuito de melhorar o desempenho das estufas solares (ativos e passivos), vários pesquisadores propuseram modificações na estrutura da estufa que estão disponíveis na literatura (AHAMED et al., 2019; GOLZAR et al., 2018; GOURDO et al., 2019; TAKI et al., 2016). São elas: Estufa solar com painéis fotovoltaicos integrados; Estufa solar com aquecedor de ar integrados; Uso da parede Norte opaca para isolar e evitar a perda de calor; Utilização de materiais de armazenamento térmico, como areia, leito de rocha, piso de concreto pintado de preto e folha de PVC; Inclinado e refletindo a parede Norte para maximizar a incidência de radiação solar;

\section{Estufas solares para secagem}

Sales et al. (2016) propõe uma nova tecnologia para secagem de grãos utilizando uma estufa solar com secador vertical. Foi feita uma comparação entre a estufa solar vertical e o método de secagem em barcaças, que é o método de secagem tradicional nesta localidade (São Cristóvão- SE -Brasil). Porém, o método tradicional possui desvantagens, visto que as amêndoas ficam sujeitas às intempéries climáticas e há necessidade de um operador de manejo dos grãos, onde o trabalhador fica exposto a condições insalubres de trabalho. A figura 1 apresenta o secador solar proposto.

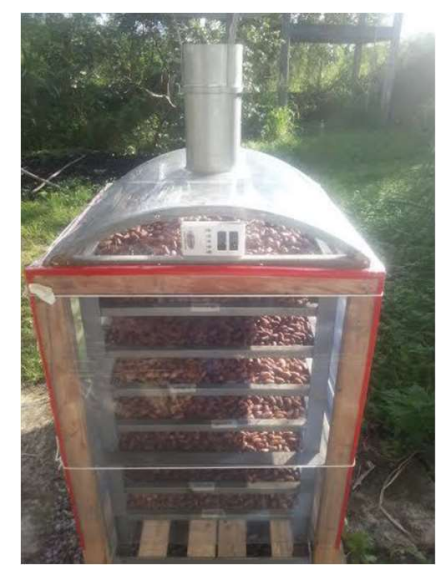

Figura 1: Secador solar de amêndoas proposto por Sales et al. (2016).

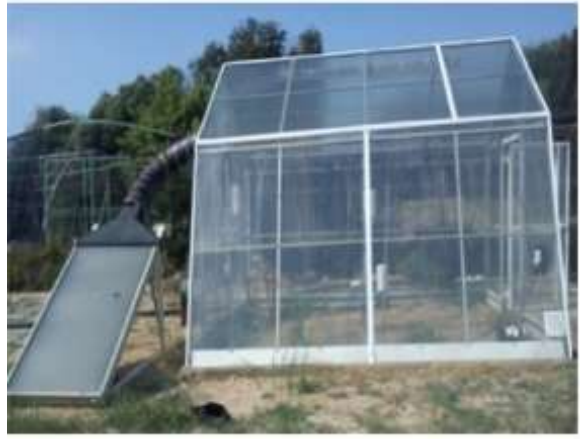

Figura 2: Secador de estufa solar proposto por Hamdi et al. (2018).

Concluiu-se que o secador solar vertical possui vantagens em relação ao método de secagem em barcaças, como redução da área necessária para a secagem, dispensa o uso de energia elétrica (para ventilação forçada), nem queima de lenha para a secagem, eliminação as condições insalubres do trabalho do operador de manejo dos grãos a céu aberto, a torre possui melhor eficiência de secagem, uma vez que consegue manter por mais tempo o calor em seu interior (no período de $11 \mathrm{~h}$ às $13 \mathrm{~h}$ ) e ainda atingindo temperaturas próximas de $50^{\circ} \mathrm{C}$, contra $36^{\circ} \mathrm{C}$ atingidos na barcaça em um mesmo momento da simulação e sob as mesmas condições inicial e de contorno. Por fim, o secador vertical segue as recomendações tanto da 
CEPLAC quando do CONCEX em relação a temperatura, o que é importante visto que a temperatura influencia diretamente nas propriedades organolépticas e consequentemente na qualidade do produto.

Hamdi et al. (2018) apresentam um estudo numérico e experimental combinado de secagem de uvas em um secador de estufa solar de modo misto com convecção forçada. O local do estudo foi em Borj Cedria, norte da Tunísia. A estufa solar secadora consiste em dois componentes principais: um coletor de ar solar onde o ar ambiente é pré-aquecido e uma estufa em forma de capela. Este sistema de secagem tem uma capacidade de carga de cerca de $130 \mathrm{~kg}$ de uva. A figura 2 mostra a estufa solar estudada.

As conclusões deste estudo estão apresentadas a seguir: A temperatura do ar de secagem dentro do secador solar variou entre $28,08^{\circ} \mathrm{Ce} 55,94^{\circ} \mathrm{C}$, durante os experimentos, o que foi suficiente para a secagem das uvas. O teor de umidade da uva Sultana foi reduzido para 18\% (base úmida) no secador de estufa levou apenas $128 \mathrm{~h}$. A eficiência do coletor de ar solar atingiu 88,52\%.

Stangerlin et al. (2009), em Santa Maria-RS-Brasil, avaliaram o uso da estufa solar para secagem das madeiras de Eucalyptus tereticornis, Eucalyptus saligna e Corymbia citriodora e realizaram uma comparação entre essa metodologia com a secagem ao ar livre. Foi desenvolvido um secador solar constituído por estruturas de madeira, cobertura com dupla camada de plástico PVC, sistema coletor interno de energia solar e sistema de circulação do ar aquecido. A figura 3 mostra a estufa proposta neste estudo.

Os resultados obtidos neste estudo mostraram que a estufa solar foi mais eficiente apresentando tempo de secagem de duas a cinco vezes menores que a secagem ao ar livre e com teor de umidade final mais baixo. A madeira seca, tanto na estufa solar quanto ao ar livre, apresentou boa qualidade, não sendo verificada a incidência de defeitos como encanoamento e colapso. O correto empilhamento e a tecnologia de secagem utilizados proporcionaram poucos empenos do tipo encurvamento. A incidência de arqueamentos, rachaduras de superfície e de topo não apresentaram diferença significativa entre a secagem em estufa solar e ao ar livre para as três madeiras estudadas.

Badaoui et al. (2019) em Bou-Ismail - Argélia, desenvolveram uma estufa solar para secagem de resíduos de tomates, visando testar o desempenho do novo secador solar como um secador de processamento de resíduos.

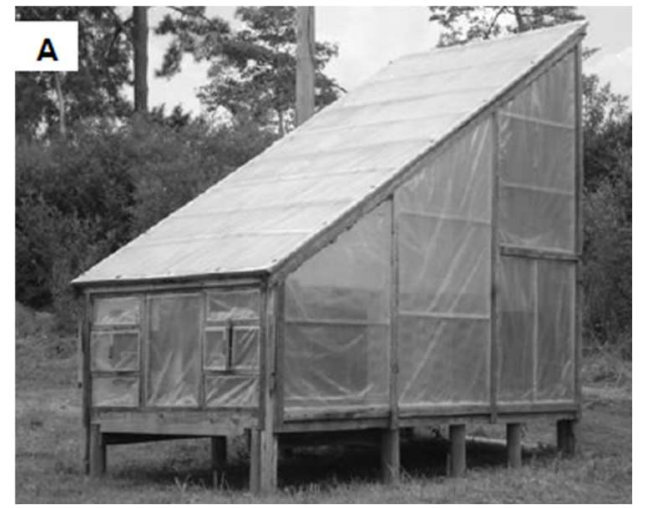

Figura 3: Estufa solar proposta por Stangerlin et al. (2009) para secagem de madeira.

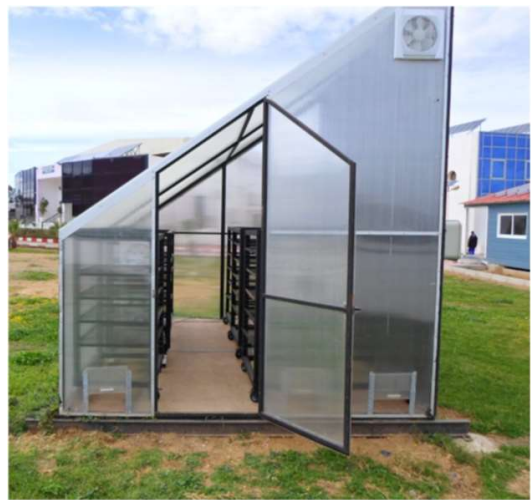

Figura 4: Estufa solar secadora proposta por Badaoui et al. (2019).

A estufa solar desenvolvida consiste em quatro paredes com um teto inclinado à $36^{\circ}$, apoiado por 
uma estrutura metálica posicionada no piso quadrado de madeira. Para uma passagem máxima de radiação, os três lados da estufa são cobertos com policarbonato transparente com valor de transmitância de $70 \%$. Além disso, o quarto lado é uma parede com isolamento preto, que é isolada termicamente com poliestireno de $5 \mathrm{~mm}$ de espessura para minimizar a perda de calor para o exterior durante o processo de secagem. Esta parede é pintada de preto para garantir a absorção dos raios solares que passam pelo policarbonato e, portanto, provoca o efeito estufa no secador. As cinco aberturas do secador são equipadas com um sistema de abertura/fechamento deslizante para controlar o fluxo de entrada e saída de ar. A figura 5 apresenta a estufa proposta neste estudo.

A estufa teve um bom desempenho, apresentando os seguintes resultados: Redução de volume (a influência está diretamente no custo de transporte e armazenamento), higiene (temperatura de secagem (entre 40 e $58^{\circ} \mathrm{C}$ ) e tempo $(5 \mathrm{~h}$ ) levam à eliminação de microrganismos), estabilização (o produto perdeu $86 \%$ do seu peso original, o que impossibilita qualquer atividade biológica, estabiliza o resíduo de tomate seco) e redução de odores emitidos.

Wilkins et al. (2018), no Reino Unido, propuseram um modelo inovador de taxas secagem de resíduos de manga. A previsão do tempo de secagem é necessária para agendar melhor o uso do secador. Os dados foram obtidos de um conjunto de balanças sem fio que pesam os resíduos durante a secagem solar após a medição inicial do teor de umidade de uma amostra. O secador solar é baseado em uma grande área retangular $\left(30 \times 25 \times 3 \mathrm{~m}^{3}\right)$ coberta por um teto transparente de policarbonato. A base de cada prateleira é feita de rede de malha de náilon para permitir que a luz do sol penetre nos níveis mais baixos e melhore o fluxo de ar. A figura 5, mostra a estrutura da estufa estudada na figura 5.

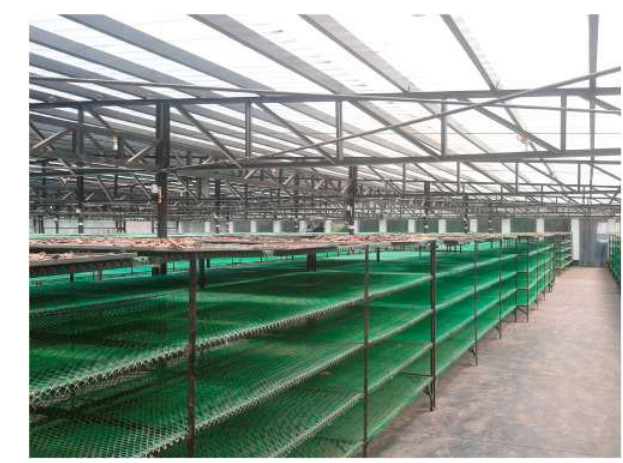

Figura 5: Método de secagem proposto por Wilkins et al. (2018).

Neste estudo foram obtidas es seguintes conclusões: Em vez de produzir um modelo temporal de teor de umidade para secagem solar de resíduos de manga, este trabalho modela em termos de taxa de secagem explicitamente. Isso tem a vantagem de que parâmetros variáveis no tempo, como temperatura, podem ser considerados. $\mathrm{O}$ modelo de secagem resultante supera os existentes na literatura. Este método elimina o impacto da temperatura do ar no equilíbrio de umidade da semente de manga e mostra que existe uma relação aproximadamente linear entre os dois para as faixas de temperatura consideradas. Este trabalho demonstra, em contraste com grande parte do trabalho da literatura, que mesmo quando a umidade de equilíbrio varia, não deve ser ignorada. A relação entre o teor de umidade e os parâmetros ambientais que a afetam pode ser obtida se um número suficientemente grande de operações de secagem estiver disponível. 
As principais conclusões obtidas nesta revisão foram as seguintes: O secador solar com efeito de estufa operando em modo ativo é melhor em comparação com o modo passivo. A conveç̧ão forçada é adequada para culturas com alto teor de umidade, enquanto a convecção natural pode ser usada para culturas com baixo teor de umidade. A cor, a qualidade, o sabor e o valor nutritivo do produto seco são melhores em secagem solar do que a secagem ao sol. O secador de estufa PV/T integrado é a melhor opção para locais remotos onde a eletricidade não está facilmente disponível. $\mathrm{O}$ uso de material de armazenamento térmico dentro do secador solar com efeito estufa aumenta a temperatura interna da estufa que reduz o período de secagem. A parede norte isolada previne a perda de calor para os arredores e melhora o desempenho do secador de estufas. O pré-aquecimento do ar usando queimador de GLP, biomassa ou coletor solar pode ser usado para aumentar a eficiência do secador.

\section{Estufas solares para cultivo protegido}

Golzar et al. (2018), na Suíça, estudaram otimizar o desempenho de estufas na intenção de reduzir a quantidade de energia por unidade de cultivo produzida. Revisaram mais de 30 modelos de efeito estufa existentes e diferentes algoritmos são combinados para propor um modelo de rendimento energético integrado. O objetivo principal foi entender o comportamento dinâmico das condições climáticas e o crescimento das culturas tanto quanto possível para investigar o desempenho real da estufa por meio de um modelo integrado. $\mathrm{O}$ modelo proposto neste estudo pode ser usado como uma ferramenta de suporte à decisão para a construção de novas estufas, de acordo com sua condição climática apropriada ou com o recondicionamento de estufas existentes o que pode ajudar os produtores a melhorar a operação das estufas, como determinar limites favoráveis e definir pontos de temperatura, concentração de $\mathrm{CO}_{2}$ e umidade para obter os melhores resultados para consumo de energia, rendimento, impactos ambientais, benefício econômico, etc.
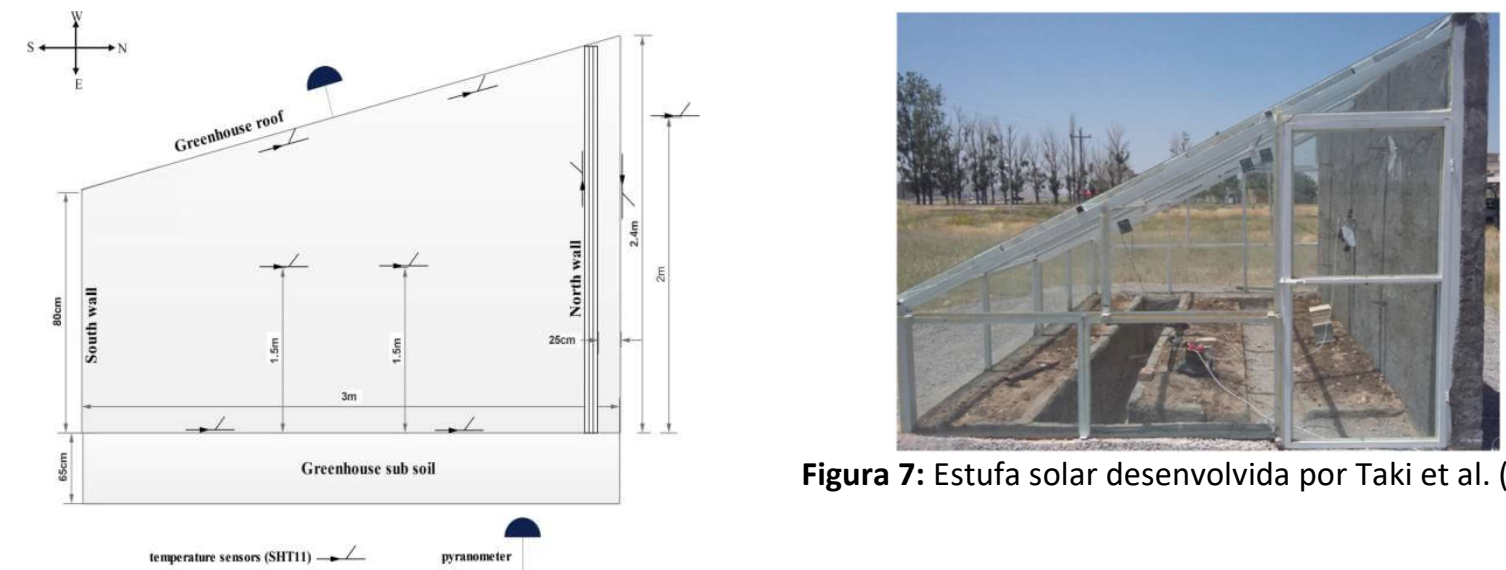

Figura 7: Estufa solar desenvolvida por Taki et al. (2016).

Figura 6: Estufa solar desenvolvida por Mohammadi et al. (2018).

Mohammadi et al. (2018) apresentam um modelo dinâmico e validação experimental para estimar as variáveis do ambiente interno em uma estufa semi-solar na província do leste do Azerbaijão, no Irã. A figura 6 mostra o design da estufa construída para este estudo. Usando a mesma metodologia, pode 
desenvolver modelos para prever o consumo de combustível, emissão de $\mathrm{CO}_{2}$ e outras produções agrícolas (rendimento) nas estufas. A modelagem do consumo de combustível, a emissão de $\mathrm{CO}_{2}$, o rendimento e o consumo de energia com base em parâmetros sociais e técnicos abririam novas portas para os avanços na agricultura e na modelagem. Taki et al. (2016), no Azerbaijão - Irã, tiveram como objetivo deste estudo modelar e avaliar experimentalmente as funções de transferência de calor e massa em uma estufa solar inovadora com tela térmica. A figura 7 mostra a estufa semi-solar desenvolvida neste estudo.

As conclusões principais deste estudo mostram que o uso de tela térmica à noite (12 h) no outono mostrou que este método pode diminuir o uso de combustíveis fósseis em até $58 \%$ e assim diminuir o custo final e a poluição do ar. Este isolamento móvel causou cerca de $15^{\circ} \mathrm{C}$ de diferença entre a temperatura do ar exterior e interior. A tela térmica interna pode diminuir a flutuação da temperatura da cultura à noite. A utilização deste método pode diminuir a emissão de $\mathrm{CO}_{2}$, o custo final e melhorar a qualidade e a quantidade de culturas. Este método pode melhorar a situação das culturas e diminuir o risco de algumas doenças, como Botrytis e requeima.

Alguns autores, em Shenyang - China, propuseram um novo tipo de cobertura deslizante em uma estufa solar economizadora de energia (SEG), visando solucionar problemas em relação à captura e equilíbrio de energia em localidades temperaturas externas extremamente baixas. O objetivo deste estudo foi comparar o desempenho de captura e distribuição de energia do SEG com o SG tradicional.

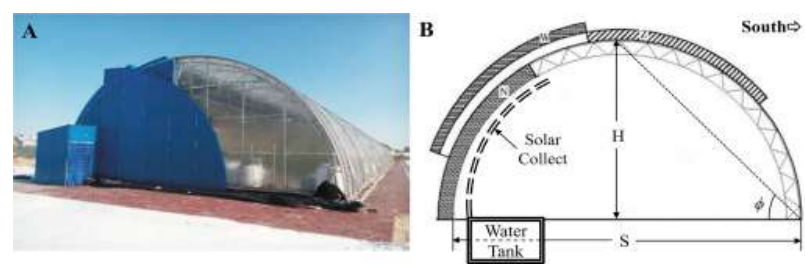

Figura 8: Estufa solar proposta por Tong et al. (2018).

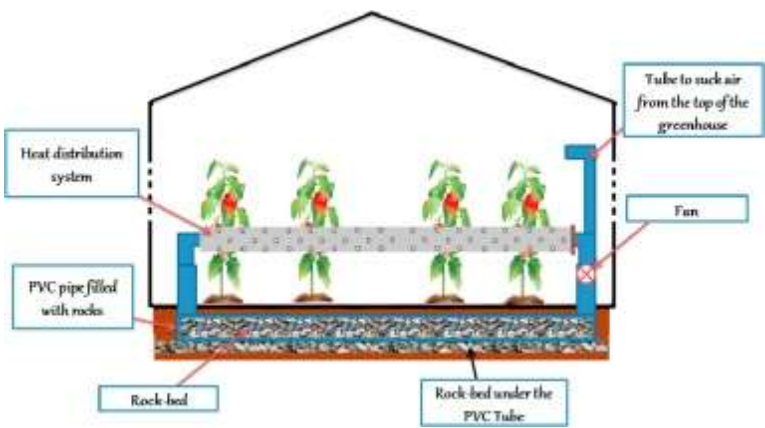

Figura 9: Estufa solar proposta Gourdo et al. (2019).

As conclusões principais deste estudo mostram que o ângulo do telhado e a forma da superfície sul transparente das estufas têm efeitos substanciais na captura e distribuição total da energia solar. 0 design do SEG moveu o cume para frente e aumentou o ângulo do teto de iluminação em $15^{\circ}$, o que melhora a relação de aspecto para melhor ganho de energia no inverno e desempenho de temperatura. Aumentou, em comparação com a LSG, a captura diária de energia no inverno em pelo menos $3 \%$, aumentando a abertura efetiva em $16 \%$, diminuindo a carga de resfriamento no verão em $15 \%$ e melhorando a uniformidade de distribuição de Norte a Sul. Ele também eliminou o sombreamento das paredes leste e oeste, alterando a estrutura tradicional do SG de três lados da parede para apenas uma parede lateral. A capacidade total do SEG, com armazenamento ativo de calor e facilidade de recuperação, pode gerenciar a energia capturada de forma mais eficaz e mostrou um aumento considerável da temperatura mínima da noite de inverno em cerca de $3-5{ }^{\circ} \mathrm{C}$. A nova estufa adotou uma forma de cobertura deslizante com placa de aço de isolamento térmico em vez da manta noturna espessa, e isso melhora a capacidade de remoção de poeira para uma 
transmissividade de cobertura constante e as necessidades operacionais para eventos de chuva. Além disso, o SEG tem a capacidade de controle automático e operações de precisão, gerenciamento proativo de energia e alocação oportuna.

Gourdo et al. (2019), em Agadir - Marrocos, estudaram a eficácia de um sistema solar de aquecimento de estufas utilizando leito rochoso. Este sistema armazena o excesso de calor da estufa durante o dia e o restitui à noite, que é adequado para fins agrícolas durante o período mais frio do ano. O sistema de aquecimento solar com efeito de estufa utilizando o leito rochoso é um sistema rentável, de fácil instalação, que não polui a atmosfera e reduz o custo do aquecimento. A figura 9 mostra o design da estufa proposta neste estudo.

As conclusões principais obtidas neste experimento foram as seguintes: Como a estufa equipada com o sistema de armazenamento de energia solar foi resfriada durante o dia e aquecida à noite, sua umidade relativa foi naturalmente maior durante o dia e menor durante a noite. A temperatura interna durante a noite é $3^{\circ} \mathrm{C}$ maior em comparação com a estufa convencional e $4,7^{\circ} \mathrm{C}$ em comparação com o exterior. Além disso, este sistema tem um efeito positivo no rendimento do tomate, que foi melhorado em $22 \%$ em comparação com a estufa convencional.

Ahamed et al. (2019), Cuce et al. (2016) e Taki et al. (2018) apresentaram uma revisão bibliográfica das diferentes técnicas de economia de energia que podem ser aplicadas para reduzir os custos de aquecimento incluindo projetos de eficiência energética em estufas. As principais conclusões que os autores encontraram foram as seguintes:

A orientação Leste-Oeste da estufa é mais eficiente em termos de energia para a estufa de inverno em latitudes mais altas ao norte, e o potencial de economia de energia pode ser significativamente diferente com base na relação comprimento-largura utilizada; $\mathrm{O}$ uso de paredes opacas no lado Norte reduz o consumo de energia consideravelmente; Cerca de $20 \%$ da energia pode ser economizada usando qualquer tela de energia à noite em estufas de inverno; Até $80 \%$ de economia de energia pode ser obtida por meio de um retrofit adequado de estufas convencionais, com um período de retorno de 4 a 8 anos, dependendo das condições climáticas e do tipo de cultivo.

Os módulos fotovoltaicos semitransparentes (isolamento térmico de vidro solar como produto comercial) podem ser considerados materiais de fachadas e telhados em estufas para fins multifuncionais. A eletricidade gerada pode ser usada para alimentar sistemas de iluminação, irrigação e bombas de calor; 0 uso adequado do armazenamento sazonal de energia térmica por meio de trocadores de calor verticais no solo pode facilmente atender à demanda de aquecimento de estufas em diferentes regiões climáticas. Para tais aplicações, o polietileno pode ser uma boa opção de material isolante com baixa condutividade térmica e baixo custo; Sistemas de bomba de calor assistida por energia solar podem atender a demanda de aquecimento e resfriamento de estufas de maneira econômica; Os coletores de vento são dispositivos ideais para resfriamento passivo e ventilação de estufas. Eles desempenham um papel significativo na redução da demanda de resfriamento das estufas na temporada de verão; Janelas de tubos de vácuo são muito promissoras para minimizar a perda de calor da cobertura da estufa. Elas têm potencial para reduzir o 
consumo de energia orientada para o efeito estufa e as emissões de carbono; A utilização de LEDs azuis e vermelhos provou ser uma luz alternativa para plantas que podem manter a fotossíntese durante a noite. Estes dispositivos de iluminação são baratos e promissores em termos de economia de energia; Os PCMs (materiais de mudança de fase) podem ser utilizados em aplicações de estufas, juntamente com coletores térmicos solares, para aumentar o conteúdo de energia térmica do sistema, reduzindo o custo do aquecimento de ambientes. O uso da tela térmica interna pode diminuir a necessidade de combustíveis fósseis em até $58 \%$. O uso deste método pode diminuir a emissão de $\mathrm{CO}_{2}$ e custo final e melhorar a qualidade e quantidade de culturas.

\section{CONCLUSÕES}

Trabalhos recentes indicam claramente que a demanda de aquecimento representa $70 \%$ a $80 \%$ de uma estufa convencional. Nesse sentido, visando o uso racional de energia com foco na economia e sustentabilidade, existem várias técnicas para reduzir energia elétrica de uma estufa. As opções precisam ser selecionadas com base nos requisitos da produção, localização e recursos financeiros disponíveis. Com base na revisão realizada, as seguintes conclusões podem ser tiradas:

O secador solar com efeito de estufa operando em modo ativo é melhor em comparação com o modo passivo; O secador de estufa PV/T integrado é a melhor opção para locais remotos onde a eletricidade não está facilmente disponível; A parede norte isolada previne a perda de calor e melhora o desempenho da secagem; A estufa em forma de vão único na orientação Leste-Oeste recebe a radiação solar máxima durante estações frias, podendo reduzir a perda de energia em uma média de 68\%; O ângulo do telhado tem efeitos substanciais na captura e distribuição total da energia solar; $\mathrm{O}$ uso de leito rochoso para aquecimento da estufa pode aumentar o rendimento em $22 \%$ comparado com uma estufa convencional; O uso da tela térmica interna pode diminuir a necessidade de combustíveis fósseis em até $58 \%$; Os módulos fotovoltaicos semitransparentes podem ser considerados materiais de fachadas e telhados em estufas para fins multifuncionais. A eletricidade gerada pode ser usada para alimentar sistemas de iluminação, irrigação e bombas de calor; O Polietileno podo ser usado como isolante térmico, pois possui baixa condutividade térmica e baixo custo; Sistemas de bomba de calor assistida por energia solar podem atender a demanda de aquecimento e resfriamento de estufas de maneira econômica.

Os coletores de vento são dispositivos ideais para resfriamento passivo e ventilação de estufas. Janelas de tubos de vácuo são muito promissoras para minimizar a perda de calor da cobertura da estufa. A utilização de LEDs azuis e vermelhos provou ser uma luz alternativa para plantas que podem manter a fotossíntese durante a noite.

Os materiais de mudança de fase (PCMs) podem ser utilizados em apliçções de estufas, juntamente com coletores térmicos solares, para aumentar o conteúdo de energia térmica do sistema; Sistemas de bomba de calor assistida por energia solar podem atender a demanda de aquecimento e resfriamento de estufas de maneira econômica.

A principal causa da demanda de aquecimento das estufas se dá pelas características de construção 
pobres e resistência térmica insuficiente dos materiais de fachada utilizados nos sistemas atuais de estufas. Atualmente, o carvão é amplamente utilizado para aquecimento de estufas convencionais, porém, seu uso causa quantidades significativas de emissões de carbono, gerando problemas ambientais. Portanto, soluções definitivas baseadas em tecnologias de energia renovável e sustentável são necessárias para reduzir a energia consumida no setor de estufas e para deter as emissões de carbono relacionadas ao efeito estufa. 0 investimento em uma estufa solar fornece um retorno positivo para os agricultores após um período que varia entre 4 e 8 anos, dependendo das condições climáticas e do tipo de cultura.

\section{REFERÊNCIAS}

AHAMED, M. D. S.; GUO, H.; TANINO, K.. Energy saving techniques for reducing the heating cost of conventional greenhouses. Biosystems Engineering, v.178, p.9-33, 2019. DOI: http://doi.org/10.1016/j.biosystemseng.2018.10.017

BADAOUI, O.; HANINI, S.; DJEBLI, A.; HADDAD, B.; BENHAMOU, A.. Experimental and modelling study of tomato pomace waste drying in a new solar greenhouse: Evaluation of new drying models. Renewable Energy, v.133, p.144-155, 2019. DOI: http://doi.org/10.1016/j.renene.2018.10.020

CUCE, E.; HARJUNOWIBOWO, D.; CUCE, P. M.. Renewable and sustainable energy saving strategies for greenhouse systems: A comprehensive review. Renewable and Sustainable Energy Reviews, v.64, p.34-59, 2016. DOI: http://doi.org/10.1016/i.rser.2016.05.077

GOLZAR, F.; HEEREN, N.; HELLWEG, S.; ROSHANDEL, R.. A novel integrated framework to evaluate greenhouse energy demand and crop yield production. Renewable and Sustainable Energy Reviews, v.96, p.487-501, 2018. DOI: http://doi.org/10.1016/j.rser.2018.06.046

GOURDO, L.; FATNASSI, H.; TISKATINE, R.; WIFAYA, A.; DEMRATI, H.; AHAROUNE, A.; BOUIRDEN, L.. Solar energy storing rock-bed to heat an agricultural greenhouse. Energy, v.169, p.206-212, 2019. DOI:

http://doi.org/10.1016/j.energy.2018.12.036

HAMDI, I.; KOOLI, S.; ELKHADRAOUI, A.; AZAIZIA, Z.; ABDELHAMID, F.; GUIZANI, A.. Experimental study and numerical modeling for drying grapes under solar greenhouse. Renewable Energy, v.127, p.936-946, 2018. DOI: http://doi.org/10.1016/j.renene.2018.05.027

MOBTAKER, H. G.; AJABSHIRCHI, Y.; RANJBAR, S. F.; MATLOOBI, M.. Solar energy conservation in greenhouse: Thermal analysis and experimental validation. Renewable Energy, v.96, p.509-519, 2016. DOI:

http://doi.org/10.1016/j.renene.2016.04.079

MOHAMMADI, B.; RANJBAR, S. F.; AJABSHIRCHI, Y.. Application of dynamic model to predict some inside environment variables in a semi-solar greenhouse. Information Processing in Agriculture, v.5, n.2, p.279-288,
2018. DOI: http://doi.org/10.1016/j.inpa.2018.01.001

NTINAS, G. K.; FRAGOS, V. P.; NIKITA-MARTZOPOULOU, C. $\mathrm{H}$.. Thermal analysis of a hybrid solar energy saving system inside a greenhouse. Energy Conversion and Management, v.81, p.428-439, 2014. Dol: http://doi.org/10.1016/j.enconman.2014.02.058

PEREIRA, E. B.; MARTINS, F. R.; GONÇALVES, A. R.; COSTA, R. S.; LIMA, F. L.; RÜTHER, R.; ABREU, S. L.; TIEPOLO, G. M.; PEREIRA, S. V.; SOUZA, J. G.. Atlas brasileiro de energia solar. 2 ed. São José dos Campos: INPE, 2017. DOI: http://doi.org/10.34024/978851700089

PEREIRA, E. B.; MARTINS, F. R.; ABREU, S. L.; RÜTHER, R.. Atlas Brasileiro de Energia Solar. Programa das Nações Unidas para o Meio Ambiente. São José dos Campos, 2006

SALES, J. H.; CÂNDIDA, T.. Efeito da temperatura sobre a amêndoa de cacau: secador vertical. Revista Gestão Inovação e Tecnologia, v.6, n.3, p.3437-3446, 2016. DOI: http://dx.doi.org/10.7198/s2237-072220160003015

STANGERLIN, D. M.; SANTINI, E. J.; SUSIN, F.; MELO, R.; GATTO, R. D. A.; HASELEIN, C. R.. Uso de estufa solar para secagem de madeira serrada. Ciênc. Florest., Santa Maria, v.19, n.4, p.461-472, 2009. DOI:

http://dx.doi.org/10.5902/19805098900.

TAKI, M.; ROHANI, A.; RAHMATI-JONEIDABAD, M.. Solar thermal simulation and applications in greenhouse. Information Processing in Agriculture, v.5, n.1, p.83-113, 2018. DOI: http://doi.org/10.1016/j.inpa.2017.10.003

TAKI, M.; AJABSHIRCHI, Y.; RANJBAR, S. F.; ROHANI, A. E.; MATLOOBI, M.. Modeling and experimental validation of heat transfer and energy consumption in an innovative greenhouse structure. Information Processing in Agriculture, v.3, n.3, p.157-174, 2016. DOI: http://doi.org/10.1016/j.inpa.2016.06.002

WILKINS, R.; BRUSEY, J.; GAURA, E.. Modelling uncontrolled solar drying of mango waste. Journal of Food Engineering, v.237, p.44-51, 2018. DOI: http://doi.org/10.1016/j.jfoodeng.2018.05.012

A CBPC - Companhia Brasileira de Produção Científica (CNPJ: 11.221.422/0001-03) detém os direitos materiais desta publicação. Os direitos referem-se à publicação do trabalho em qualquer parte do mundo, incluindo os direitos às renovações, expansões e disseminações da contribuição, bem como outros direitos subsidiários. Todos os trabalhos publicados eletronicamente poderão posteriormente ser publicados em coletâneas impressas sob coordenação da Sustenere Publishing, da Companhia Brasileira de Produção Científica e seus parceiros autorizados. Os (as) autores (as) preservam os direitos autorais, mas não têm permissão para a publicação da contribuição em outro meio, impresso ou digital, em português ou em tradução. 